\title{
石墨炔结构及性能的理论研究
}

\author{
李会学* 王晓峰李志锋潘素娟 \\ (甘肃省新型分子材料设计与功能重点实验室 天水师范学院生命科学与化学学院 天水 741001)
}

\begin{abstract}
摘要 石墨炔作为一种新的稳定的碳同素异形体, 由于其独特的结构和性能, 预计可广泛地应用于纳米材料及器件中. 在本文中, 我们采用 B3LYP/6-31 $+\mathrm{G}$ *理论研究了其结构参数、Wiberg 键级以及芳香性. 计算结果表明, 所有的碳原子 的 $\mathrm{p}$-电子参与形成了非定域的 $\pi$-键, 使得所有 $\mathrm{C}-\mathrm{C}$ 键长平均化. 苯环的核独立化学位移比乙炔形成的不等边六边形 的更负, 表明苯环的芳香性更强. 该化合物的拓扑性质与 Wiberg 键级的计算结果也一致. 另外, 该化合物的 LUMO $(0.27 \mathrm{eV})$ 带宽大于其 HOMO $(0.24 \mathrm{eV})$ 的带宽，表明它应该是 $\mathrm{n}$-型材料. 当采用对称性破缺方法重新对该化合物优化后， 计算结果显示该化合物含有 3.6 个未成对电子, 并具有一定的化学反应活性.
\end{abstract}

关键词 石墨炔; 芳香性; Wiberg 键级; AIM; 奇电子

\section{Theoretical Study on the Structure and Properties of Graphdiyne}

\author{
Li, Huixue* Wang, Xiaofeng Li, Zhifeng Pan, Sujuan \\ (Key Laboratory for New Molecule Design and Function of Gansu Education Department, College of Life Science and \\ Chemistry, Tianshui Normal University, Tianshui 741001)
}

\begin{abstract}
The graphdiyne, as a new stable carbon allotrope, is expected to be widely applied to nanosciences and devices due to unique structure and properties. In this paper we investigated the structural parameters, Wiberg bond indices, and the aromaticity of graphdiyne at the B3LYP/6-31+ $\mathrm{G}^{*}$ level. The calculating results indicated all the p-electrons of the carbons were able to form delocalized $\pi$-bonds and all the lengths of $\mathrm{C}-\mathrm{C}$ bonds were to become average. The aromaticity of all the benzene rings was stronger than the scalene hexagon due to more negative the nucleus independent chemical shift (NICS) value. The topological properties of the compound were in good agreement with those discussed in Wiberg Bond Orders. The LUMO bandwidth $(0.27 \mathrm{eV})$ of the title compound was larger than the HOMO bandwidth $(0.24 \mathrm{eV})$, it indicates that the graphdiyne should be n-type material. The calculation of the odd electrons by the broken symmetry method showed that the compound contains 3.6 effectively unpaired electrons and possesses enhanced chemical reactivity.

Keywords graphdiyne; aromaticity; Wiberg bond indices; AIM; odd electrons
\end{abstract}

\section{Introduction}

During the past three decades, scientists have successfully synthesized some new carbon allotropes, such as fullerenes, carbon nanotubes and graphene,$^{[1-4]}$ accordingly the relative synthesis method, special properties and new application of the carbon allotropes have been become the forefront and hot in internationally academic research either experimentally or theoretically. ${ }^{[5-13]}$ Because of carbon's three hybridization states $\left(\mathrm{sp}^{3}, \mathrm{sp}^{2}\right.$, and $\left.\mathrm{sp}\right)$, the atoms of this element can combine with each other and produce numerous allotropes; there are graphite $\left(\mathrm{sp}^{2}\right)$, diamond $\left(\mathrm{sp}^{3}\right)$ in the nature, and other allotropes, for example, the fullerene $\left(\mathrm{sp}^{2}\right)$, carbon nanotube $\left(\mathrm{sp}^{2}\right)$, and graphene $\left(\mathrm{sp}^{2}\right)$ have been found in past decades too. Graphene possesses planar two-dimensional structure and unique mechanical and electronic properties, it was able to be ex- pected to apply to composites, ${ }^{[14,15]}$ gas sensors, ${ }^{[16,17]}$ spintronic devices ${ }^{118]}$ and transparent electrodes for light emitting diodes and photovoltaics. ${ }^{[1,20]}$ Graphdiyne, which is similar to the graphene, has been predicted theoretically by Baughman, ${ }^{[21]}$ it exists networks of combinations of $\mathrm{sp}^{2}$ and sp hybridized carbons. The substructures of the molecule has been synthesized by Haley, ${ }^{[22,23]}$ in which there were star- and trefoil-shaped polyethynyl aromatic structures, the properties of the synthesized substructures have been characterized as well, UV-vis spectrum indicated enhanced electron delocalization throughout the extended $\pi$-system. Recently Li demonstrated a methodology to generate large area graphdiyne films on the surface of copper via a cross-coupling reaction using hexaethynylbenzene, in which the carbon-carbon triple bond (sp) is a basic connecting unit. The film indicated a semiconductor property with conductivity of $2.516 \times 10^{-4} \mathrm{~S} \cdot \mathrm{m}^{-1} .^{[24,25]}$

*E-mail: 1i_hx2001@126.com

Received September 28, 2012; published December 14, 2012.

Project supported by the Key Laboratory for New Molecule Material Design and Function of Tianshui Normal University and the Scientific Research Projects of Young and Middle-aged in Tianshui Normal University (No. TSA1116), the Key Discipline of Tianshui Normal University, and the Fund of Educational Commission of Gansu Province (No. 1108-03).

项目受天水师范学院新型分子材料设计与功能重点实验室和天水师范学院中青年教师科研基金(No. TSA1116)、天水师范学院重点学科和甘肃省教育 厅科研基金(No. 1108-03)资助. 
The theoretical studies of adsorption, electronic and magnetic property about graphene have been done numerously, ${ }^{[26-36]}$ for the graphdiyne, there were considerable references to research its properties too. Lu et al. reported that the calculated band gap of graphdiyne was $1.10 \mathrm{eV}$ with the GW many-body theory, however, one was 0.44 $\mathrm{eV}$ with the density functional theory; in addition, a remarkable electron-hole binding energy, which was about $0.55 \mathrm{eV}$ with the GW-Bethe-Salpeter equation calculation, ${ }^{[37]}$ indicated that the optical absorption was dominated by excitonic effects. Narita et al. calculated electronic band structures of graphdiyne using a full-potential linear combination of atomic orbitals method in the local-density approximation, the calculated results showed the optimized lattice lengths was $9.44 \AA$ and graphdiyne was semiconductors with moderate band gaps. ${ }^{[38,39]}$ Shuai et al. investigated the charge mobility of graphdiyne using density functional theory coupled with Boltzmann transport equation, the calculated electron mobility can reach the order of $10^{5} \mathrm{~cm}^{2} /(\mathrm{V} \bullet \mathrm{s})$ and be one orders of magnitude greater than that of the hole mobility. ${ }^{[40]}$ In order to deeply understand the structure-property relationship, in this article, we investigate and discuss the aromaticity of graphdiyne with nuclear independent chemical shifts (NICS); the strength of the bonds were characterized by Wiberg bond indices using natural bond orbital (NBO) $;^{[41-43]}$ in addition, the chemical reactivity was researched with the odd electrons by the broken symmetry method as well.

\section{Computational details}

We initially optimized the geometry of graphdiyne employing the hybrid DFT method B3LYP/6-31+G*, which includes a mixture of Hartree-Fock exchange with density functional exchange correlation. Stationary points were detected by harmonic frequency computations at the same theoretical level. The structures by B3LYP were further refined using the second-order Møller-Plesset (MP2) procedure with the same basis set. The MP2/6-31+G* method produced essentially the same structures as DFT, with bond lengths systematically shortened by about $2 \%$. Natural bond orbital (NBO) analyses were performed to gain insight into the bonding pattern of the compound. To assess the aromatic character of the species, the nucleus independent chemical shifts (NICS) were also calculated using the gauge-independent atomic orbital (GIAO) ${ }^{[44-47]}$ procedure at the B3LYP/6-31 $+\mathrm{G}^{*}$ level. Atoms in molecules (AIM) theory have been used to investigate the topological properties of the critical points in the graphdiyne structure. All the calculations were carried out by using Gaussian 03 program. ${ }^{[48]}$

\section{Results and discussion}

\subsection{Geometry and bonding analysis}

The bonding parameters of the title compound on equilibrium structure were collected in Table 1. It was found that the graphdiyne has $D_{2 h}$ symmetry, so we only discussed the marked atoms and the rings (A, B and D) in Figure 1 . Obviously both the big six-membered rings (D ring) are scalene hexagons, of which the long sides are comprised of alternant $\mathrm{C}-\mathrm{C}$ and $\mathrm{C} \equiv \mathrm{C}$ bonds, the calculated $\mathrm{C}(1)-\mathrm{C}(3), \mathrm{C}(3) \equiv \mathrm{C}(4)$ and $\mathrm{C}(4)-\mathrm{C}(5)$ bond lengths are $1.411,1.225$, and $1.356 \AA$, respectively. Owing to the conjugation effect, these single bonds become shorter and triple bonds are longer than the typical ones (1.54 $\AA$ for single bond and $1.20 \AA$ for triple bond), especially for the $\mathrm{C}(4)-\mathrm{C}(5)$ bond $(1.356 \AA)$ between both the $\mathrm{C} \equiv \mathrm{C}$ bonds, it is very similar to a typical $\mathrm{C}=\mathrm{C}$ double bond $(1.34 \AA)$. The short side $C(1)-C(2)$ of the scalene hexagon is from the benzene ring and the bond length is $1.429 \AA$, which is somewhat longer than the $\mathrm{C}=\mathrm{C}$ bond of a single benzene $(1.39 \AA)$ and is very close to the one of graphene $(1.42 \AA)$. The above indicates that the p-electrons of all the carbon atoms form $\pi$-delocalized bond. After including dynamic correlation by MP2 calculations, the bond lengths of the equilibrium geometry are in good accord with values obtained using B3LYP/6-31+ $\mathrm{G}^{*}$ calculations (see Table 1). The largest difference is only 0.002 $\AA$ from the $\mathrm{C}(4)-\mathrm{C}(5)$ bond and the relative error is within $2 \%$.

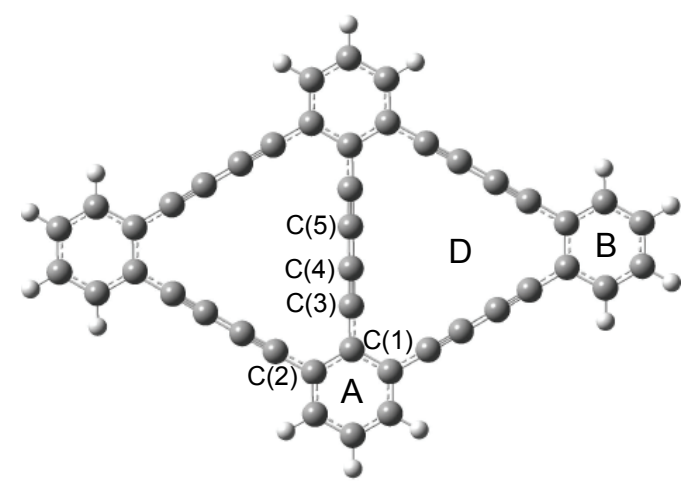

Figure 1 The geometry of the graphdiyne.

Table 1 Selected optimized geometrical parameters and the Wiberg bond orders using $6-31+\mathrm{g}^{*}$ basis set

\begin{tabular}{lcccccc}
\hline & \multicolumn{2}{c}{ Bond length/ } & & \multicolumn{2}{c}{ Wiberg Bond order } \\
\cline { 2 - 3 } \cline { 6 - 6 } & B3LYP & MP2 & & B3LYP & MP2 \\
\hline $\mathrm{C}(1)-\mathrm{C}(2)$ & 1.429 & 1.429 & & 1.255 & 1.3055 \\
$\mathrm{C}(1)-\mathrm{C}(3)$ & 1.411 & 1.411 & & 1.164 & 1.0954 \\
$\mathrm{C}(3)-\mathrm{C}(4)$ & 1.225 & 1.224 & & 2.465 & 2.6094 \\
$\mathrm{C}(4)-\mathrm{C}(5)$ & 1.356 & 1.354 & & 1.191 & 1.1345 \\
\hline
\end{tabular}

To assess the magnitude of multiple bonding, we calculated the Wiberg bond order (WBO) using NBO routines in Gaussian 03 (Table 1). The WBO values of the $\mathrm{C}(1)-\mathrm{C}(3), \mathrm{C}(3) \equiv \mathrm{C}(4)$ and $\mathrm{C}(4)-\mathrm{C}(5)$ bond in the long side of the scalene hexagon using B3LYP/6-31+ $\mathrm{G}^{*}$ are $1.164,2.465$, and 1.191 respectively, obviously the $\mathrm{C}(3) \equiv$ $\mathrm{C}(4)$ bond possesses still the characteristic of triple bond, the above data are correspondence with the expectation. The WBO of $\mathrm{C}(1)=\mathrm{C}(2)$ bond is 1.255 and larger than the $\mathrm{C}(1)-\mathrm{C}(3)$ and $\mathrm{C}(4)-\mathrm{C}(5)$ bond, it implies $\mathrm{C}(1)=\mathrm{C}(2)$ bond is stronger than $\mathrm{C}(1)-\mathrm{C}(3)$ bond. The values of WBO using MP2/6-31+ $\mathrm{G}^{*}$ are slight smaller than those by $\mathrm{B} 3 \mathrm{LYP} / 6-31+\mathrm{G}^{*}$, however, the same tendency is found. 


\subsection{Aromaticity of the title compound}

Nucleus-independent chemical shifts (NICS), which is based directly on cyclic electron delocalization, has become the most widely aromaticity criteria due to its simplicity and efficiency. Compared with other aromaticity criteria, NICS has several advantages as following: it does not require reference standards; it only shows a modest dependence on the ring size (magnetic susceptibility depends on the square of the ring area); it does depend on the number of $\pi$ electrons as well (the $10 \pi$ electron systems give significantly higher values than those with six $\pi$ electrons); ${ }^{[49]}$ Importantly, NICS correlates well with other aromaticity indexes based on energetic, geometric, and other magnetic criteria; at last it can be computed easily using standard quantum chemical programs such as Gaussian, ADF, and deMon. The Bq ghost atoms (Banquo, that is, ghost atoms, taken from Macbeth) are used to designate the positions for the NICS evaluations. For planar or nearly planar molecules, the $\pi$ orbitals have their maximum density at points $1 \AA$ above the ring center, and the $\sigma$-orbital contributions to NICS will be very little, ${ }^{[49]}$ so we adopted the recommended point ( $1 \AA$ above the ring center) as the position of NICS evaluations measure of the graphdiyne. In general, the more negative of the GIAO magnetic shielding tensor is, the stronger the aromaticity will be.

Both the benzene rings $\mathrm{A}$ and $\mathrm{B}$ have larger NICS values (Table 2), they are -9.804 and -10.433 , respectively, which is close to one of a benzene molecule $(-10.20)$, it indicates that both the benzene rings exist strong aromaticity and the positions are more stable not to happen easily chemical reaction. The big ring $\mathrm{D}$ has negative NICS value too, however, it is only -0.428 , which shows the scalene hexagon possesses weak aromaticity.

Table 2 Electron densities and Laplacians of the ring A, B and D at ring critical points using B3LYP/6-31 $+\mathrm{G}^{*}$ with the AIM theory (all quantities are in atomic units) and NICS values ( $1 \AA$ above the ring center)

\begin{tabular}{cccccc}
\hline Ring & $\rho\left(r_{\mathrm{C}}\right)$ & $\lambda_{1}$ & $\lambda_{2}$ & $\lambda_{3}$ & NICS \\
\hline $\mathrm{A}$ & 0.0194 & -0.0145 & 0.0811 & 0.0826 & -9.804 \\
$\mathrm{~B}$ & 0.0198 & -0.0148 & 0.0811 & 0.0868 & -10.433 \\
$\mathrm{D}$ & $3.84 \times 10^{-5}$ & $-2.29 \times 10^{-5}$ & $1.84 \times 10^{-4}$ & $1.92 \times 10^{-4}$ & -0.428 \\
\hline
\end{tabular}

In addition, we plotted the 3-dimensional iso-surfaces of the calculated charge density (shown in Figure 2), the values of the density used to plot the surfaces are 0.001 and 0.0001 a.u. respectively. The shapes of the density iso-surfaces are very similar in both cases, however, the iso-surface of 0.001 a.u. electron density concentrates on the framework of all the carbon atoms and one of 0.0001 a.u. value comparatively diffuse on the framework, this indicates that the center of the scalene hexagon has less electron. The consequence agrees well with the result of NICS analysis.

\subsection{AIM analysis}

In AIM analysis, the topological properties of the scalar field electron density $\left(\rho\left(r_{\mathrm{C}}\right)\right)$ can be described by the numbers and the categories of the critical points. A critical point is the spatial position where the first derivative of the $\rho\left(r_{\mathrm{C}}\right)$ is zero. According to the critical point's curvature obtained by calculating the second derivative of the $\rho\left(r_{\mathrm{C}}\right)$,
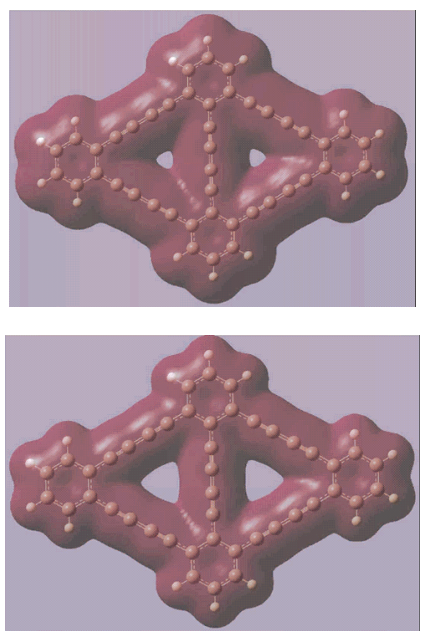

Figure 2 The 3-dimensional iso-surfaces of the calculated charge density (the density value of 0.001 a.u. on the top and 0.001 a.u. value on the bottom).

the type of the critical point can be defined. The Hessian matrix of electron density is composed by nine secondary derivatives of $\rho\left(r_{\mathrm{C}}\right)$ in three dimensions. The three eigenvalues $\left(\lambda_{1}, \lambda_{2}\right.$ and $\left.\lambda_{3}\right)$ can be acquired by performing a diagonalized operator on Hessian matrix. The sum of the three eigenvalues is equal to Laplacian of the electron density $\left(\nabla^{2} \rho\left(r_{\mathrm{C}}\right)=\lambda_{1}+\lambda_{2}+\lambda_{3}\right)$. Among the three eigenvalues, if two of them are negative and the other is positive, the corresponding critical point is designated as the bond critical point (BCP), indicating the linkage between the two atoms; if two of them are positive and the other is negative, the corresponding critical point is designated as the ring critical point $(\mathrm{RCP})$, indicating the existence of the ring structure. In general, the $\rho\left(r_{\mathrm{C}}\right)$ of a $\mathrm{BCP}$ is related to the strength of the bond: the larger the $\rho\left(r_{\mathrm{C}}\right)$ is, the stronger the bond will be; the smaller the $\rho\left(r_{\mathrm{C}}\right)$ is, the weaker the bond will be. The $\nabla^{2} \rho\left(r_{\mathrm{C}}\right)$ of a BCP reflects the characteristic of the bond. If $\nabla^{2} \rho\left(r_{\mathrm{C}}\right)<0, \mathrm{BCP}$ charges will be concentrated, and the more negative the $\nabla^{2} \rho\left(r_{\mathrm{C}}\right)$ is, the more covalent the property is; if $\nabla^{2} \rho\left(r_{\mathrm{C}}\right)>0$, BCP charges will be dispersed, and the more positive the $\nabla^{2} \rho\left(r_{\mathrm{C}}\right)$ is, the more ionic the property is. ${ }^{[50]}$

The electronic density of the $\mathrm{C}(1)-\mathrm{C}(2), \mathrm{C}(1)-\mathrm{C}(3)$, $\mathrm{C}(3)-\mathrm{C}(4)$ and $\mathrm{C}(4)-\mathrm{C}(5)$ bonds of graphdiyne at the bond critical point and its Laplacian are given in Table 3. The values of the $\rho\left(r_{\mathrm{C}}\right)$ of $\mathrm{C}(1)-\mathrm{C}(2)\left(0.2932 \mathrm{e} / \mathrm{a}_{0}{ }^{3}\right)$ and

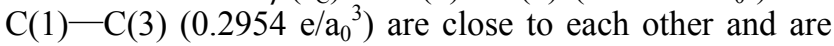
the smallest among all the bonds, the $\rho\left(r_{\mathrm{C}}\right)$ of $\mathrm{C}(3)-\mathrm{C}(4)$ $\left(0.3923 \mathrm{e} / \mathrm{a}_{0}{ }^{3}\right)$ is the largest, the $\rho\left(r_{\mathrm{C}}\right)$ of $\mathrm{C}(4)-\mathrm{C}(5)$ $\left(0.3196 \mathrm{e} / \mathrm{a}_{0}{ }^{3}\right)$ bond is slight smaller than one of $\mathrm{C}(3)-\mathrm{C}(4)$ and larger than one of the $\mathrm{C}(1)-\mathrm{C}(2)$, the results are corresponding to those from Wiberg Bond Orders mentioned above, obviously the $\mathrm{C}(3)-\mathrm{C}(4)$ bond possesses the characteristic of the $\mathrm{C} \equiv \mathrm{C}$ triple bond, the $\mathrm{C}(4)-\mathrm{C}(5)$ bond is stronger than the $\mathrm{C}(1)-\mathrm{C}(2)$ and $\mathrm{C}(1)-\mathrm{C}(3)$ bonds due to the conjugation of both the $\pi$ bonds which locate in horizontal and vertical to the graphdiyne plane. All the Laplacian of the electron density, $\nabla^{2} \rho\left(r_{\mathrm{C}}\right)$, are negative, it implies these bonds belong to covalent property. In addition, there are three calculated RCP for graphdiyne owing to two positive $\lambda$ and one negative $\lambda$ 
(shown in Table 3), which correspond to two benzene rings and one scalene hexagon ring, however, the electric density of the D ring appears smaller than those of the A and B rings, the topological properties are in good agreement with those discussed in NICS analysis.

Table 3 Electron densities and Laplacians of graphdiyne at bond critical points using B3LYP/6-31 $+\mathrm{G}^{*}$ with the AIM theory (all quantities are in atomic units)

\begin{tabular}{cccccc}
\hline Bond & $\rho\left(r_{\mathrm{C}}\right)$ & $\nabla^{2} \rho\left(r_{\mathrm{C}}\right)$ & $\lambda_{1}$ & $\lambda_{2}$ & $\lambda_{3}$ \\
\hline $\mathrm{C}(1)-\mathrm{C}(2)$ & 0.2932 & -0.7525 & -0.6073 & -0.5047 & 0.3595 \\
$\mathrm{C}(1)-\mathrm{C}(3)$ & 0.2954 & -0.8010 & -0.5864 & -0.5353 & 0.3207 \\
$\mathrm{C}(3)-\mathrm{C}(4)$ & 0.3923 & -1.143 & -0.6300 & -0.5924 & 0.0796 \\
$\mathrm{C}(4)-\mathrm{C}(5)$ & 0.3196 & -0.9226 & -0.6062 & -0.5913 & 0.2749 \\
\hline
\end{tabular}

\subsection{DOS analysis}

A carrier density of states (DOS), which is a number of carrier states in an interval of energy per unit volume, can be explained the charge transfer in the simulated graphene layer, ${ }^{[51]}$ so we have analyzed the DOS of the graphdiyne sheet. In this paper, the periodic boundary condition and the generalized gradient approximation for the exchange-correlation energy functional, which are in the version of Perdew, Burke and Ernzerh (PBE functional), were employed in order to obtain the DOS of the graphdiyne sheet (shown in Figure 3). The DOS can be divided into both groups by the occupied or virtual orbitals, Mulliken population analysis shows that the orbital energies between -4.33 and $-4.60 \mathrm{eV}$ are from the lowest-energy virtual $2 p$ orbitals of the carbon atoms, these orbitals form the LUMO bandwidth; the orbital energies between -5.04 and $-4.80 \mathrm{eV}$ (the main contributions from the highestenergy occupied $2 p$ orbitals of the carbon atoms) form the HOMO bandwidth. It has been pointed out that when the LUMO bandwidth is larger than the HOMO bandwidth, the electron conductance of the material is larger than the hole one, the material performs n-type property, and vice versa. ${ }^{[52]}$ The LUMO bandwidth $(0.27 \mathrm{eV})$ of the title compound is larger than the HOMO bandwidth $(0.24 \mathrm{eV})$, it indicates that the graphdiyne should be n-type material, which is consistent with the calculated result by Shuai, ${ }^{[40]}$ the experimental result demonstrated that the graphdiyne film possessed electrical characteristics.

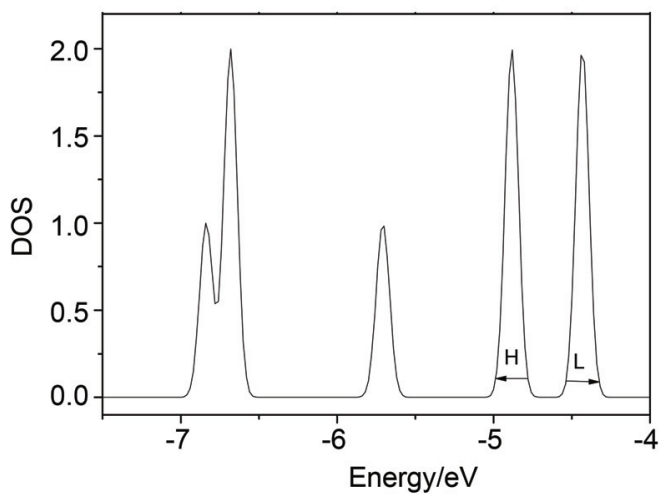

Figure 3 Density of states (DOS) vs. energy (in eV) of the graphdiyne. $\mathrm{L}$ and $\mathrm{H}$ represent the electron (LUMO) and hole (HOMO) bandwidths respectively.

\subsection{Odd electron analysis}

Sheka et al. ${ }^{[52]}$ found that with the number of benzenoid cycles increasing for fused aromatic compounds, the total energies of the molecules were lower and the odd electrons increased as the open-shell unrestricted broken symmetry (UBS) approach was employed, later it was found that analogous things happened with fullerene $\mathrm{C}_{60}{ }^{[53]}$ fullerene $\mathrm{C}_{70},{ }^{[54,55]}$ carbon nanotubes and graphene, ${ }^{[56-58]}$ so it is necessary to check the strength of this electron correlation about graphdiyne.

The spatial and spin symmetries of the wave function are broken by mixing the frontier molecular orbitals in UBS approach, in which some static electron correlation is included. ${ }^{[51]}$ Spin-contaminated energy of the UBS HF solution is much lower than one of the restricted solutions by $0.5 \%$. The calculations of odd electrons and spin quantum number were performed using AM1/PM3 of the CLUSTER-Z1 software. ${ }^{[59]}$ Compared with the closedshell restricted approach, UBS turned out the availability of 3.6 effectively unpaired electrons (the molecule is 3.6-fold radical).

Not only the UBS approach could evaluate the total number of the unpaired electrons, but it can evaluate the partial distribution over atoms which quantify the molecular chemical susceptibility and atomic chemical susceptibility (ACS), respectively, the larger ACS value is, the higher the chemical activity is. To illustrate the above said, Figure 4 presents the distribution of effectively unpaired electron over the molecule atoms. Bright-spot picture visualizes the molecule "chemical portrait", which shows these atoms have enhanced chemical reactivity, when hydrogen molecules are adsorbed by the graphdiyne, the bright-atoms are the first targets for hydrogenation.

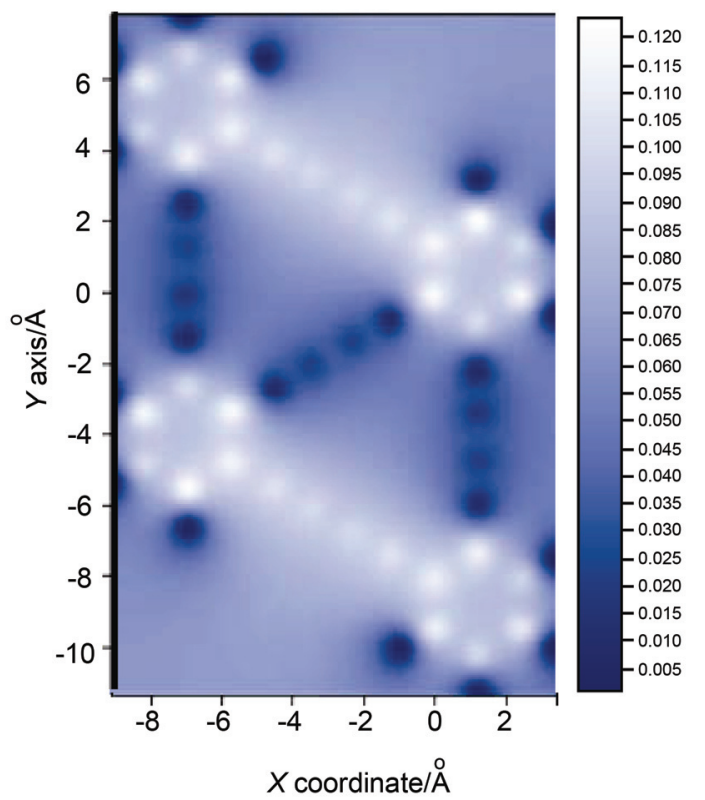

Figure 4 The distribution of effectively unpaired electrons over the graphdiyne atoms. The scale is given in a.u.

In addition, chemical hardness ${ }^{[50-61]}$ can be used to analyze molecular stability, in the framework of DFT, chemical hardness is defined as the second derivative of the total energy $E_{n}$ with respect to the number of electrons $n$ at a 
fixed external potential $v(\mathrm{r})$. It is also the second derivative of the electronic energy with respect to the number of electrons $\mathrm{n}$ based on DFT when the external potential $v(\mathrm{r})$ is kept fixed:

$$
\eta=\frac{1}{2}\left(\frac{\partial^{2} E_{n}}{\partial n^{2}}\right)_{v(r)}=\frac{1}{2}\left(\frac{\partial \mu}{\partial n}\right)_{v(r)} \approx \frac{I-A}{2}
$$

where $\mu$ is the chemical potential; $I$ and $A$ are the vertical ionization potential and electron affinity, respectively; then, using Koopmans's theorem, we can approximate hardness as:

$$
\eta \approx \frac{1}{2}\left(\varepsilon_{\mathrm{LUMO}}-\varepsilon_{\mathrm{HOMO}}\right)
$$

where the difference $\varepsilon_{\mathrm{LUMO}}-\varepsilon_{\mathrm{HOMO}}$ is the energy gap between the unoccupied and occupied orbitals. In general, the larger chemical hardness indicates the molecule is more stable. We calculated the chemical hardness of graphdiyne and $\mathrm{C} 60$, the results show the $\eta$ value $(1.55 \mathrm{eV})$ of the graphdiyne is larger than one $(1.37 \mathrm{eV})$ of C60, obviously C60 is more active. Compared with the planar configuration of the graphdiyne, there is considerable tension in the cage structure of $\mathrm{C} 60$, which derives from the five-membered ring, so it can be understanded that C60 is more active than the graphdiyne.

\section{Conclusions}

The structure, Wiberg bond indices, and aromaticity of graphdiyne were investigated at the B3LYP/6-31+G* level. The calculating results indicated all the p-electrons of the carbons were able to form delocalized $\pi$-bond and all the $\mathrm{C}-\mathrm{C}$ bond lengths were to become average. The aromaticity of the scalene hexagon was weaker than both the benzene rings due to larger NICS value. The topological properties of the compound were in good agreement with those discussed in Wiberg Bond Orders. The DOS analysis indicated that the graphdiyne was n-type material which agreed with the experiment. The calculation of the odd electrons showed that the compound is 3.6-fold radical and possesses enhanced chemical reactivity.

\section{Acknowledgements}

We thank Prof. Sheka for his helpful calculation about the odd electron.

\section{References}

[1] Kroto, H. W.; Heath, J. R.; Obrien, S. C.; Curl, R. F.; Smalley, R. E. Nature 1985, 318, 162.

[2] Iijima, S. Nature 1991, 354, 56.

[3] Kroto, H.; Allaf, A.; Balm, S. Chem. Rev. 1991, 91, 1213.

[4] Novoselov, K.; Geim, A.; Morozov, S.; Jiang, D.; Zhang, Y.; Dubonos, S.; Grigorieva, I.; Firsov, A. Science 2004, 306, 666.

[5] Dennler, G.; Scharber, M. C.; Brabec, C. J. Adv. Mater. 2009, 21, 1323.

[6] Thompson, B. C.; Frechet, J. M. J. Angew. Chem., Int. Ed. 2008, 47, 58.

[7] Thilgen, C.; Diederich, F. Chem. Rev. 2006, 106, 5049.

[8] Guldi, D. M.; Illescas, B. M.; Atienza, C. M.; Wielopolskia, M.;
Martin, N. Chem. Soc. Rev. 2009, 38, 1587.

[9] Veldman, D.; Ipek, O.; Meskers, S. C. J.; Sweelssen, J.; Koetse, M. M.; Veenstra, S. C.; Kroon, J. M.; van Bavel, S. S.; Loos, J.; Janssen, R. A. J. J. Am. Chem. Soc. 2008, 130, 7721.

[10] Andrews, R.; Jacques, D.; Qian, D. L.; Rantell, T. Acc. Chem. Res. 2002, 35, 1008 .

[11] Prato, M.; Kostarelos, K.; Bianco, A. Acc. Chem. Res. 2008, 41, 60.

[12] Kim, S. N.; Rusling, J. F.; Papadimitrakopoulos, F. Adv. Mater. 2007, 19, 3214.

[13] Britz, D. A.; Khlobystov, A. N. Chem. Soc. Rev. 2006, 35, 637.

[14] Stankovich, S.; Dikin, D.; Dommett, G.; Kohlhaas, K.; Zimney, E.; Stach, E.; Piner, R.; Nguyen, S.; Ruoff, R. Nature 2006, 442, 282.

[15] Watcharotone, S.; Dikin, D.; Stankovich, S.; Piner, R.; Jung, I.; Dommett, G.; Evmenenko, G.; Wu, S.; Chen, S.; Liu, C. Nano Lett. 2007, 7, 1888 .

[16] Blake, P.; Brimicombe, P.; Nair, R.; Booth, T.; Schedin, F.; Ponomarenko, L.; Morozov, S.; Gleeson, H.; Hill, E.; Geim, A. Nano Lett. 2008, 8, 1704.

[17] Barbolina, I.; Novoselov, K.; Morozov, S.; Dubonos, S.; Missous, M.; Volkov, A.; Christian, D.; Grigorieva, I.; Geim, A. Appl. Phys. Lett. 2006, 88, 013901.

[18] Tombros, N.; Jozsa, C.; Popinciuc, M.; Jonkman, H.; Van Wees, B. Nature 2007, 448, 571.

[19] Di, C.; Wei, D.; Yu, G.; Liu, Y.; Guo, Y.; Zhu, D. Adv. Mater. 2008, $20,3289$.

[20] Wang, X.; Zhi, L.; Mullen, K. Nano Lett. 2008, 8, 323.

[21] Baughman, R.; Eckhardt, H.; Kertesz, M. J. Chem. Phys. 1987, 87, 6687.

[22] Marsden, J. A.; Haley, M. M. J. Org. Chem. 2005, 70, 10213.

[23] Haley, M. M. Pure Appl. Chem. 2008, 80, 519.

[24] Liu, H.; Xu, J.; Li, Y. Acc. Chem. Res. 2010, 43, 1496.

[25] Li, G.; Li, Y.; Liu, H.; Guo, Y.; Li, Y.; Zhua, D. Chem. Commun. 2010, $46,3256$.

[26] Chakarova Käck, S.; Schröder, E.; Lundqvist, B.; Langreth, D. Phys. Rev. Lett. 2006, 96, 146107.

[27] Leenaerts, O.; Partoens, B.; Peeters, F. Phys. Rev. B 2008, 77, 125416.

[28] Heine, T.; Zhechkov, L.; Seifert, G. Phys. Chem. Chem. Phys. 2004, 6,980 .

[29] Schedin, F.; Geim, A.; Morozov, S.; Hill, E.; Blake, P.; Katsnelson, M.; Novoselov, K. Nat. Mater. 2007, 6, 652.

[30] Zhang, Y.; Chen, Y.; Zhou, K.; Liu, C.; Zeng, J.; Zhang, H.; Peng, Y. Nanotechnology 2009, 20, 185504.

[31] Giannozzi, P.; Car, R.; Scoles, G. J. Am. Chem. Soc. 2003, 118 1003.

[32] Miura, Y.; Kasai, H.; Dino, W.; Nakanishi, H.; Sugimoto, T. J. Appl. Phys. 2003, 93, 3395.

[33] Montoya, A.; Truong, T.; Sarofim, A. J. Phys. Chem. A 2000, 104, 6108 .

[34] Jeloaica, L.; Sidis, V. Chem. Phys. Lett. 1999, 300, 157.

[35] Sheka, E. F.; Chernozatonskii, L. A. Int. J. Quantum Chem. 2010, $110,1938$.

[36] Xu, B.; Yin, J.; Xia, Y. D.; Wan, X. G.; Jiang, K.; Liu, Z. G. Appl. Phys. Lett. 2010, 96, 163102.

[37] Luo, G.; Qian, X.; Liu, H.; Qin, R.; Zhou, J.; Li, L.; Gao, Z.; Wang, E.; Mei, W. N.; Lu, J.; Li, Y.; Nagase, S. Phys. Rev. B 2011, 84, 075439.

[38] Narita, N.; Nagai, S.; Suzuki, S.; Nakao, K. Phys. Rev. B 1998, 58, 11009 .

[39] Narita, N.; Nagai, S.; Suzuki, S.; Nakao, K. Phys. Rev. B 2000, 62, 11146.

[40] Long, M.; Tang, L.; Wang, D.; Li, Y.; Shuai, Z. ACS Nano 2011, 5, 2593.

[41] Wiberg, K. Tetrahedron 1968, 24, 1083.

[42] Liang, X. Q.; Pu, X. M.; Tian, A. M. Acta Chim. Sinica 2010, 68, 1568. (梁晓琴, 蒲雪梅, 田安民, 化学学报, 2010, 68, 1568.)

[43] Li, H. X.; Wang, X. F.; Li, Z. F.; Zhu, Y. C. Acta Phys.-Chim. Sinica 2012, 28, 1094.

[44] Schleyer, P. V.; Maerker, C.; Dransfeld, A.; Jiao, H.; Hommes, N. J. Am. Chem. Soc 1996, 118, 6317.

[45] Schleyer, P. V.; Jiao, H.; Hommes, N.; Malkin, V.; Malkina, O. J. Am. Chem. Soc. 1997, 119, 12669.

[46] Steiner, E.; Fowler, P.; Jenneskens, L. Angew. Chem., Int. Ed. 2001, $40,362$.

[47] Ditchfield, R. Mol. Phys. 1974, 27, 789.

[48] Frisch, M. J.; Trucks, G. W.; Schlegel, H. B.; Scuseria, G. E.; Robb, 
M. A.; Cheeseman, J. R.; Zakrzewski, V. G.; Montgomery, J. A.; Stratmann, R. E.; Burant, J. C.; Dapprich, S.; Millam, J. M.; Daniels, A.; Stratmann, R. E.; Burant, J. C.; Dapprich, S.; Millam, J. M.; Daniels, A. D.; Kudin, K. N.; Strain, M. C.; Farkas, O.; Tomasi, J.; Barone, V.; Cossi, M.; Cammi, R.; Mennucci, B.; Pomelli, C.; Adamo, C.; Clifford, S.; Ochterski, J.; Petersson, G. A.; Ayala, P. Y.; Cui, Q.; Morokuma, K.; Malick, D. K.; Rabuck, A. D.; Raghavachari, K.; Foresman, J. B.; Cioslowski, J.; Ortiz, J. V.; Stefanov, B. B.; Liu, G.; Liashenko, A.; Piskorz, P.; Komaromi, I.; Gomperts, R.; Martin, R. L.; Fox, D. J.; Keith, T.; Al-Laham, M. A.; Peng, C. Y.; Nanayakkara, A.; Gonzalez, C.; Challacombe, M.; Gill, P. M. W.; Johnson, B. G.; Chen, W.; Wong, M. W.; Andres, J. L.; Head-Gordon, M.; Replogle, E. S.; Pople, J. A. Gaussian 03, Revision E.01, Gaussian, Inc., Wallingford, CT, 2004.

[49] Chen, Z. F.; Wannere, C. S.; Corminboeuf, C.; Puchta, R.; Schleyer, P. R. Chem. Rev. 2005, 105, 3842.

[50] Sosa, G. L.; Peruchena, N. M.; Contreras, R. H.; Castro, E. A. THEOCHEM 2002, 577, 219.

[51] Prall, M.; Wittkopp, A.; Schreiner, P. R. J. Phys. Chem. A 2001, 105,9265 .
[52] Sheka, E. F.; Razbirin, B. S.; Nelson, D. K. J. Phys. Chem. A 2011, 115,3480 .

[53] Sheka, E. F. Int. J. Quantum Chem. 2004, 100, 375.

[54] Sheka, E. F. J. Struct. Chem. 2006, 47, 593.

[55] Sheka, E. F. Central Eur. J. Phys. 2004, 2, 300.

[56] Sheka, E. F.; Chernozatonskii, L. J. Phys. Chem. C 2007, 111, 10771.

[57] Sheka, E. F.; Chernozatonskii, L. J. Exp. Theor. Phys. 2010, 110, 121.

[58] Sheka, E. F.; Chernozatonskii, L. A. Int. J. Quantum Chem. 2010, $110,1466$.

[59] Zayets, V. A. CLUSTER-Z1: Quantum-Chemical Software for Calculations in the s,p-Basis, Institute of Surface Chemistry, National Academy of Science of Ukraine, Kiev, 1990.

[60] Perdew, J. P.; Parr, R. G.; Levy, M. B. Phys. Rev. Lett. 1982, 49, 1691.

[61] Cervantes-Salguero, K.; Seminario, J. M. J. Mol. Model. 2012, 18, 4043. 